\title{
Irrigation management of agricultural reservoir with correlation feature selection based binary particle swarm optimization
}

\author{
Yahya Nur Ifriza ${ }^{1}$, Muhammad Sam'an ${ }^{2}$ \\ ${ }^{1}$ Department of Computer Science, Universitas Negeri Semarang, Indonesia \\ ${ }^{2}$ Postgradute Student, Faculty of Technology Management and Business, Universiti Tunn Husein Onn, Malaysia
}

\begin{tabular}{l}
\hline \hline Article Info \\
\hline Article history: \\
Received Feb 8, 2021 \\
Revised March 7, 2021 \\
Accepted March 20, 2021 \\
\hline
\end{tabular}

\section{Keywords:}

Support vector machine Correlation feature Binary particle swarm Irrigation management Agricultural reservoir

\begin{abstract}
The requirement for the applied innovation to farming water system is especially required for supplies, as rural water system focuses. Supplies as one of horticulture water system asset focus that are regularly constraints identified with the conveyance of repository water stream, this brought about lopsided dissemination of rural water system and the term of control of agrarian water system that streams from water system asset focuses. At the point when ranchers need to change the water system way, it will take a long effort to make another water system way. From these troubles to convey rural water systems simpler, it is important to plan a specialist framework to decide rural water system choices. A few researchers focused on improved quality of plant. There have been limited studies concerned with irrigation management Therefore, this research intends to design The objectives of this research are optimization irrigation management of agricultural reservoirs with CFS-BPSO. The consequences of this investigation demonstrate that the exactness of the utilization of the SVM calculation is $62.32 \%$, while after utilizing the CFS calculation precision of $84.12 \%$ is acquired and exactness of ten SVM calculations by applying a blend of CFS highlight choice. also, BPSO $91.84 \%$.
\end{abstract}

This is an open access article under the CC BY-SA license.

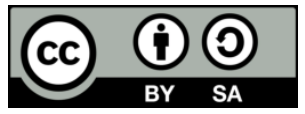

\footnotetext{
Corresponding Author:

Yahya Nur Ifriza,

Department of Computer Science, Universitas Negeri Semarang,

Sekaran, Gunungpati, Semarang 50229, Indonesia.

Email: yahyanurifriza@mail.unnes.ac.id
}

\section{INTRODUCTION}

The value and practical period of farming water system improvement or recovery will decrease if there isn't sufficient legitimate upkeep and operational administration to look after them, feasible and suitable from all invested individuals in water system water use exercises. A stream is a level or land 75 where surface water comes from downpour, snow melts, or ice unites to a point at low height [1]. Supplies of good-quality water system water are required to diminish in a few districts because of expanded metropolitan mechanical rural rivalry, accessible freshwater supplies should be utilized all the more effectively [2]. A day-by-day soil dampness balance was utilized to foresee dissipation and happening from which harvest yields were assessed [3]. Improvement of profits to water assets could emerge out of creating better caliber and higher value crops for homegrown and unfamiliar business sectors utilizing improved water system procedures [4]. To foresee a choice in information mining can utilize arrangement methods [5]. Support Vector Machine [6]-[8], K-Nearest 
Neighbor [9]-[11], Decision Tree [12], [13], and Artificial Neural Network [12], [14] are instances of arrangement calculations.

The requirement for the applied innovation to farming water system is especially required for supplies, as rural water system focuses. Supplies as one of horticulture water system asset focus that is regularly constrained identified with the conveyance of repository water stream, this brought about lopsided dissemination of rural water system and the term of control of agrarian water system that streams from water system asset focuses, thusly the developments are required for the dispersion of rural water system should be possible dependent on the necessities Water system of farmland by ranchers [15]. A water-saving water system can be utilized rather than nonstop flood water system to utilize the groundwater [16]. Water system stretch, or soil water accessibility for crop use, soil type, evapotranspiration request, dispersion of plant root framework and saltiness, and harmfulness of explicit particles on crop development [17].

There are three stages to create accuracy cultivating innovation. The initial step depends on ordinary agrarian innovation, by escalating machines to lessen works. The subsequent advance includes the improvement of planning procedures, variable-level of machine innovation, and presentation of the fundamental framework choice emotionally supportive network. The third step applies innovation well, the model applied in past research was to coordinate the utilization of fitting innovation in farming [18].

At the point when ranchers need to change the water system way, it will take a long effort to make another water system way. From these troubles to convey rural water systems simpler, it is important to plan a specialist framework to decide rural water system choices. A few researchers focused on improved quality of plant. There have been limited studies concerned with irrigation management Therefore, this research intends to design the objectives of this research are optimization irrigation management of agricultural reservoir with CFS-BPSO.

\section{METHOD} in Figure 1.

The interaction utilized by an agronomist (master) to decide the measure of water system is showed

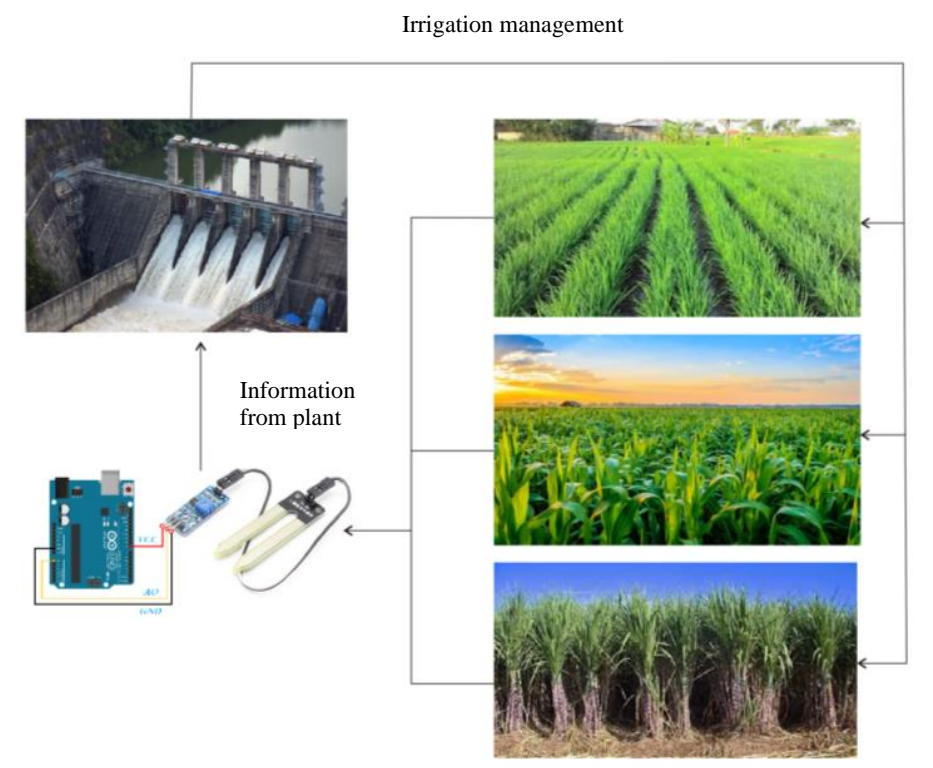

Figure 1. Cycle utilized design to decide irrigation management.

This article uses sensor data for all data models and is compiled from the conditions of each plant. includes agricultural humidity sensor data, reservoir water level data, data on types of agricultural commodities. Data may vary based on the data set available from the source. This dataset has 11 attributes that is (1) water level of reservoir (kaw); (2) moisture of land 1 (kel1); (3) moisture of land 2 (kel2); (4) land humidity 3 (kel3); (5) moisture of land 4 (kel4); (6) land humidity 5 (kel5); (7) type of commodity land 1 (koml1); (8) type of commodity land 2 (koml2); (9) kinds of land commodity 3 (koml3); (10) type of commodity land 4 (koml4); (11) commodity land type 5 (koml5).

In this examination, the blend of CFS and BPSO was completed as an element choice. CFS is utilized to decrease the elements of the dataset dependent on the connection among's highlights and target class yet doesn't associate with different highlights. BPSO is utilized to locate the best blend of highlights. The characterization strategy utilized is the Support Vector Machine calculation. From the arrangement results, we 
will get an expansion in precision from Support Vector Machine when the blend of CFS and BPSO is applied [8]. The flowchart of optimization CFS-BPSO is depicted in Figure 2.

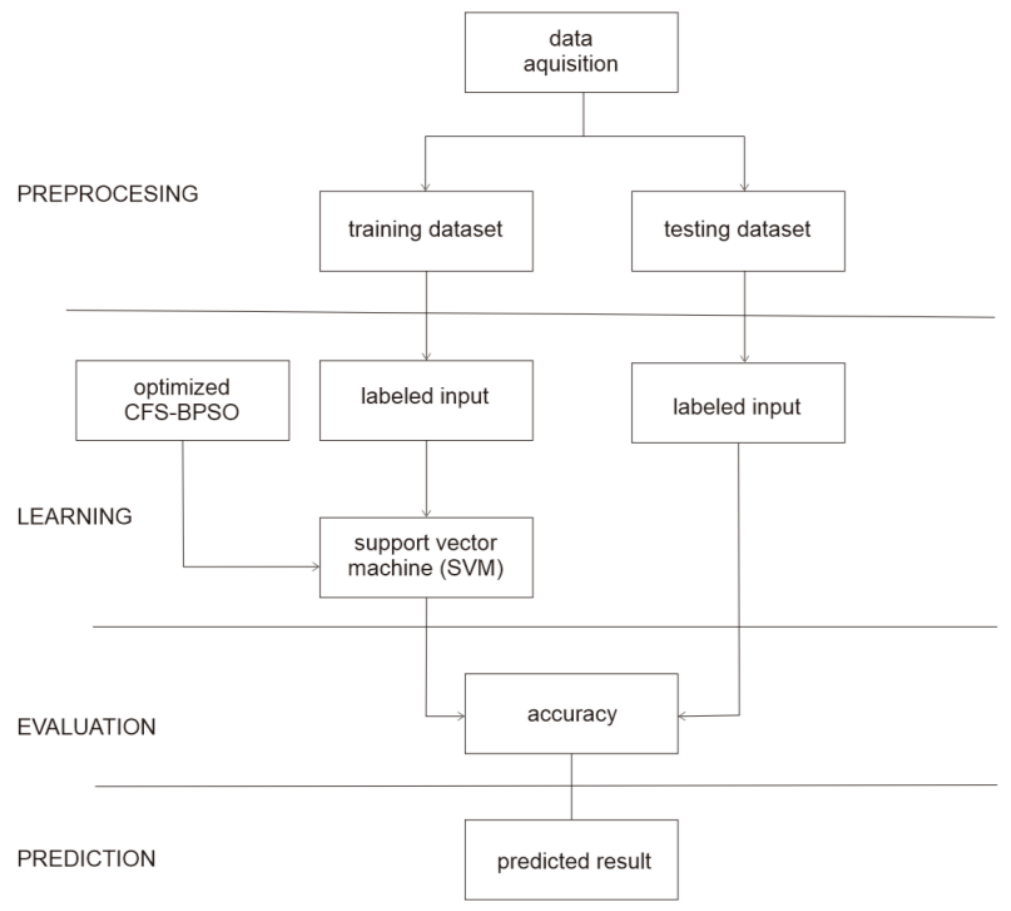

Figure 2. Flowchart of Optimization CFS-BPSO

Relationship-based Component Choice (CFS) is a channel calculation that positions subset ascribes as indicated by heuristic assessment capacities dependent on connection [18]. CFS will assess includes by thinking about the prescient abilities of each component and the degree of repetition between them. If the relationship among's traits and class is known, and the connection between's each character is given, at that point the connection can be anticipated.

PSO was presented in 1995 by Kennedy and Eberhart dependent on a friendly reproduction model known as a stochastic enhancement calculation [19], [20]. Examination and applications on Particle Swarm Optimization (PSO) have expanded quickly since its development and this has brought about many improved PSO calculations in different kinds of advancement issues. In PSO, the hyper boundary is streamlined by two highlights; calculation and its capacity [21]. This has been applied in PSO calculations to take care of the streamlining issues or to improve the first PSO [22]. Heaps of work and investigation of the adequacy of PSO contrasted with other AI and multitude knowledge calculation for designing and software engineering issue has been finished by specialists to assess its exhibitions [23]. It can be joined PSO-SVM to figure horticulture water utilization [24]. The idea of PSO is that every molecule is flown in search space to locate the best arrangement (wellness) called pbest. At that point, the best generally esteem (worldwide worth) is called gbest. Every molecule has two vectors in particular position vectors and speed vectors to move around in search space. Every molecule has memory and every molecule will follow the best position already [24].

Support Vector Machine (SVM) was first proposed by Vladimir Vapnik. Proposed in the field of measurable learning hypothesis and primary danger minimization [25], [26]. SVM has been utilized in an assortment of issues like information characterization, picture grouping, text order, tone acknowledgment, digit acknowledgment of penmanship [27], [28].

\section{RESULTS AND DISCUSSIONS}

In this investigation, the proposed calculation testing utilizes the Python programming language by using the scikit-learn, sk-highlight and pyswarms libraries. The information utilized is a dataset taken from UCI Machine Learning. This dataset has 11 attributes. CFS will choose attributes that have the highest correlation weighting value. From the CFS process, 11 selected attributes were obtained. The list of attributes and weights of the CFS process is shown in Table 1.

J. Soft. Comp. Explor., Vol. 2, No. 1, March 2021 : 40 - 45

DOI: 
Table 1. List of attributes and results of CFS weight

\begin{tabular}{ccc}
\hline No & Attributes & CFS Weight \\
\hline 1 & kaw & 0,53212231 \\
2 & kel1 & 0,54326545 \\
3 & kel2 & 0,54356437 \\
4 & kel3 & 0,53478954 \\
5 & kel4 & 0,54587690 \\
6 & kel5 & 0,53976512 \\
7 & koml1 & 0,53987652 \\
8 & koml2 & 0,54543217 \\
9 & koml3 & 0,54667584 \\
10 & koml4 & 0,53485769 \\
11 & koml5 & 0,53212231 \\
\hline
\end{tabular}

The attributes, picked by the CFS calculation, don't generally create the best blend of characteristics. Thusly, the BPSO calculation is utilized to decide the best element mix of the credits picked by the CFS. At this stage, 11 tests are hurried to decide the best element mix. BPSO boundaries utilized in this examination have appeared in Table 2.

Table 2. BPSO parameters

\begin{tabular}{lc}
\hline Parameters & Value \\
\hline Number of computation & 50 \\
Max iteration & 100 \\
Number of particles & 50 \\
Cognitif c1 & 2,00 \\
Social c2 & 2,00 \\
\hline
\end{tabular}

At this stage, 3 tests were done, specifically the independent SVM calculation, the SVM calculation with the execution of the CFS calculation and the SVM by actualizing a blend of CFS and BPSO. In the main application, the SVM calculation will handle the CKD dataset with 11 credits. The utilization of the SVM calculation has a precision of $62.32 \%$. The aftereffects of this precision express that the SVM calculation can characterize the dataset well because the exactness results are more noteworthy than the mistake rate. Be that as it may, the consequences of this precision can be improved by applying a few preprocessing techniques. In the subsequent application, the SVM calculation will be joined with the CFS calculation. So SVM will handle the dataset with 11 attributes and 1 class. The exactness of this grouping model is $84.12 \%$. The precision of applying this model can expand the exactness of the SVM calculation by $21.8 \%$. Notwithstanding, these outcomes can in any case be improved by picking the best element mix utilizing the BPSO calculation. The third application, the SVM algorithm will be joined with the CFS and BPSO algorithm. In this usage, 6 tests are rushed to decide the best component mix. The exactness of this arrangement model can be found in Table 3.

Table 3. SVM Accuracy Results with CFS and BPSO

\begin{tabular}{ccc}
\hline Execution & Number of attributes & Value \\
\hline 1 & 11 & $91,32 \%$ \\
2 & 10 & $90,87 \%$ \\
3 & 10 & $90,58 \%$ \\
4 & 11 & $92,31 \%$ \\
5 & 11 & $93,62 \%$ \\
6 & 11 & $92,37 \%$ \\
\hline
\end{tabular}

The precision of applying this model can expand the exactness of the SVM + CFS calculation by $7.72 \%$ and can build the SVM calculation by $29.52 \%$. The correlation of the precision of every calculation application can be found in Figure 3. 


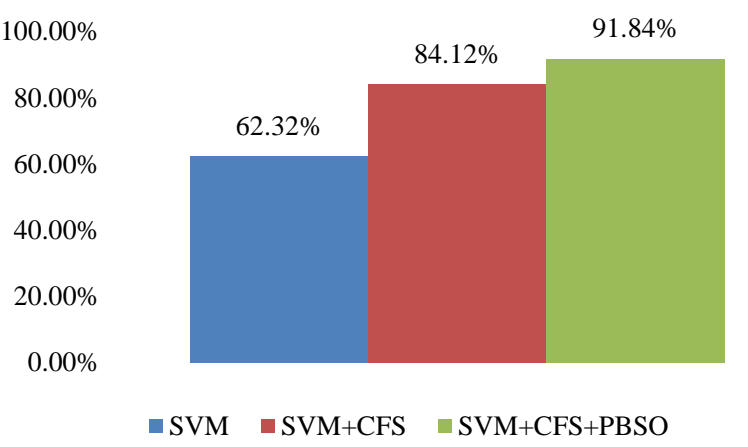

Figure 3. The comparison result SVM, CFS and BPSO

\section{CONCLUSION}

The SVM algorithm was tried by applying the CFS algorithm and the BPSO calculation utilizing a dataset. The CFS calculation is utilized to get credits with a great connection, while BPSO is utilized to acquire the best characteristic blends. The consequences of this investigation demonstrate that the exactness of the utilization of the SVM calculation is $62.32 \%$, while after utilizing the CFS calculation precision of $84.12 \%$ is acquired and exactness of ten SVM calculations by applying a blend of CFS highlight choice. also, BPSO $91.84 \%$. Subsequently, it very well may be presumed that the use of a mix of CFS and BPSO is a choice component in the SVM calculation can build the precision in diagnosing by $29.52 \%$.

\section{REFERENCES}

[1] S. A. Rahaman, S. A. Ajeez, S. Aruchamy, and R. Jegankumar, "Prioritization of sub watershed based on morphometric characteristics using fuzzy analytical hierarchy process and geographical information system - a study of kallar watershed, tamil nadu," Aquat. Procedia, vol. 4, pp. 1322-1330, 2015, doi: 10.1016/j.aqpro.2015.02.172.

[2] M. Qadir, "Crop and irrigation management strategies for saline-sodic soils and waters aimed at environmentally sustainable agriculture," Sci. Total Environ., 2003, doi: 10.1016/s00489697(03)00596-5.

[3] D. L. Martin, D. G. Watts, and J. R. Gilley, "Model and production function for irrigation management," J. Irrig. Drain. Eng., vol. 110, no. 2, pp. 149-164, 1984, doi: 10.1061/(asce)07339437(1984)110:2(149).

[4] M. Valipour, "A comprehensive study on irrigation management in Asia and Oceania," Arch. Agron. Soil Sci., vol. 61, no. 9, pp. 1247-1271, 2015, doi: 10.1080/03650340.2014.986471.

[5] N. Deb, V. Jha, A. K. Panjiyar, and R. K. Gupta, "A comparative analysis of news categorization using machine learning approaches," Int. J. Sci. Technol. Res., vol. 9, no. 1, pp. 2469-2472, 2020.

[6] S. Mayor and B. Pant, "Document classification using Support Vector Machine," Int. J. Eng. Sci. Technol., vol. 4, p. 5, 2012.

[7] A. Gupta and A. Kumar, "A new method for solving linear multi-objective transportation problems with fuzzy parameters," Appl. Math. Model., vol. 36, no. 4, pp. 1421-1430, 2012, doi: 10.1016/j.apm.2011.08.044.

[8] Sulistiana and M. A. Muslim, "Support Vector Machine (SVM) optimization using grid search and unigram to improve e-commerce review accuracy," J. Soft Comput. Explor., vol. 1, no. 1, pp. 8-15, 2020.

[9] D. A. Adeniyi, Z. Wei, and Y. Yongquan, "Automated web usage data mining and recommendation system using K-Nearest Neighbor (KNN) classification method,” Appl. Comput. Informatics, vol. 12, no. 1, pp. 90-108, 2016, doi: 10.1016/j.aci.2014.10.001.

[10] H. Shahabi, A. Shirzadi. A. Ghaderi and E. Omidvar, "Flood detection and susceptibility mapping using Sentinel-1 remote sensing data and a machine learning approach: Hybrid intelligence of bagging ensemble based on K-Nearest Neighbor classifier," Remote Sens., vol. 12, no. 2, 2020, doi: $10.3390 / \mathrm{rs} 12020266$.

[11] Z. Pan, Y. Wang, and Y. Pan, "A new locally adaptive k-nearest neighbor algorithm based on discrimination class," Knowledge-Based Syst., vol. 204, 2020, doi: 10.1016/j.knosys.2020.106185.

[12] X. Sun, S. Su, Z. Zuo, X. Guo, and X. Tan, "Modulation classification using compressed sensing and decision tree-support vector machine in cognitive radio system," Sensors (Switzerland), vol. 20, no. 5, 2020, doi: 10.3390/s20051438.

J. Soft. Comp. Explor., Vol. 2, No. 1, March 2021 : 40 - 45

DOI: 
[13] T. Lajnef et al., "Learning machines and sleeping brains: Automatic sleep stage classification using decision-tree multi-class support vector machines," J. Neurosci. Methods, vol. 250, pp. 94-105, 2015, doi: 10.1016/j.jneumeth.2015.01.022.

[14] M. Ghiassi, M. Olschimke, B. Moon, and P. Arnaudo, "Automated text classification using a dynamic artificial neural network model," Expert Syst. Appl., vol. 39, no. 12, pp. 10967-10976, 2012, doi: 10.1016/j.eswa.2012.03.027.

[15] Y. N. Ifriza, C. E. Edi, and J. E. Suseno, "Expert system irrigation management of agricultural reservoir system using analytical hierarchy process (AHP) and forward chaining method," Int. Conf. on Math. Scien. and Edu., vol. 4. no.1. pp. 74-83, 2017.

[16] R. Talebnejad and A. R. Sepaskhah, "Effects of water-saving irrigation and groundwater depth on direct seeding rice growth, yield, and water use in a semi-arid region," Arch. Agron. Soil Sci., vol. 60, no. 1, pp. 15-31, 2014, doi: 10.1080/03650340.2013.770598.

[17] N. Pirmoradian and A. R. Sepaskhah, "A very simple model for yield prediction of rice under different water and nitrogen applications," Biosyst. Eng., vol. 93, no. 1, pp. 25-34, 2006, doi: 10.1016/j.biosystemseng.2005.09.004.

[18] S. Tohidyan Far and K. Rezaei-Moghaddam, "Determinants of Iranian agricultural consultants' intentions toward precision agriculture: Integrating innovativeness to the technology acceptance model," J. Saudi Soc. Agric. Sci., vol. 16, no. 3, pp. 280-286, 2017, doi: 10.1016/j.jssas.2015.09.003.

[19] N. Gopika and A. E. A. Meena Kowshalaya, "Correlation based feature selection algorithm for machine learning," Proc. 3rd Int. Conf. Commun. Electron. Syst. ICCES 2018, pp. 692-695, 2018, doi: 10.1109/CESYS.2018.8723980.

[20] D. Aprilianto, "SVM Optimization with Correlation feature selection based binary particle swarm optimization for diagnosis of chronic kidney disease," J. Soft Comput. Explor., vol. 1, no.1, pp. 24-31, 2020.

[21] R. A., E. S. -, A. A., and B. Ibrahim, "Modifications of Particle Swarm Optimization techniques and its application on stock market: a survey," Int. J. Adv. Comput. Sci. Appl., vol. 6, no. 3, 2015, doi: 10.14569/ijacsa.2015.060315.

[22] R. H. Saputra and B. Prasetyo, "Improve the accuracy of c4.5 algorithm using particle swarm optimization ( pso ) feature selection and bagging technique in breast cancer diagnosis," J. Soft Comput. Explor., vol. 1, no.1, pp. 47-55, 2020.

[23] N. A. Hitam and A. R. Ismail, "Comparative performance of machine learning algorithms for cryptocurrency forecasting,” Indones. J. Electr. Eng. Comput. Sci., vol. 11, no. 3, pp. 1121-1128, 2018, doi: 10.11591/ijeecs.v11.i3.pp1121-1128.

[24] Y. Tang and J. Zhou, "The performance of PSO-SVM in inflation forecasting," 2015 12th Int. Conf. Serv. Syst. Serv. Manag. ICSSSM 2015, 2015, doi: 10.1109/ICSSSM.2015.7170251.

[25] J. Nayak, B. Naik, and H. S. Behera, "A Comprehensive survey on support vector machine in data mining tasks: applications \& challenges," Int. J. Database Theory Appl., vol. 8, no. 1, pp. 169-186, 2015, doi: 10.14257/ijdta.2015.8.1.18.

[26] B. Ghaddar and J. Naoum-Sawaya, "High dimensional data classification and feature selection using support vector machines," Eur.J. Oper. Res., vol. 265, no. 3, pp. 993-1004, 2018, doi: 10.1016/j.ejor.2017.08.040.

[27] D. K. Srivastava and L. Bhambhu, "Data classification using support vector machine," J. Theor. Appl. Inf. Technol., vol. 12, no. 1, pp. 1-7, 2010.

[28] J. Dou and A.P. Yunus., "Improved landslide assessment using support vector machine with bagging, boosting, and stacking ensemble machine learning framework in a mountainous watershed, Japan," Landslides, vol. 17, no. 3, pp. 641-658, 2020, doi: 10.1007/s10346-019-01286-5. 